\title{
Designing Safety Critical Interactions: Hunting Down Human Error
}

Susanne Boll

University of Oldenburg

Oldenburg and OFFIS Institute

for IT, Germany

Susanne.Boll@uol.de

Philippe Palanque

ICS-IRIT

University of Toulouse, France

palanque@irit.fr

\section{Alexander G. Mirnig}

Center for Human-Computer

Interaction

University of Salzburg, Austria

alexander.mirnig@sbg.ac.at
Jessica Cauchard

Ben Gurion University of the Negev

Beer Sheva, Israel

jcauchard@bgu.ac.il

Margareta Holtensdotter

Lützhöft

Department of Maritime Studies

mhl@hvl.no

Michael S. Feary

NASA Ames Research Center

michael.s.feary@nasa.gov

\section{Abstract}

Human error at the time of operation (i.e. when the system is in use) are implicated in most incidents involving safety critical systems. In many domains, control and command interfaces are composed of a multitude of devices and machines from different brands in different generations have been crammed together. The resultant bridging of functions across devices, the decision making, the overview, the handling of partially imprecise or conflicting information are often just offloaded to the human. Thus, there appears to be a need to shift the attention from avoiding human error (at operation time) to avoiding error during design. In this workshop, we aim to provide a forum to discuss such a paradigm shift and the implication on the methods and tools for designing and evaluating $\mathrm{HCI}$ technology in safety-critical environments.

\section{Author Keywords}

Design errors, human error, safety critical systems,

transportation, energy, medicine.

\section{ACM Classification Keywords}

-Human-centered computing Human computer interaction (HCI) $\bullet$ Hardware Robustness $\sim$ Safety critical systems -Hardware Robustness Fault tolerance $\sim$ Error detection and error correction 


\section{Background}

Safety Critical Environments, i.e., systems whose failure either endanger human life or cause drastic economic losses, form the technological backbone of today's society and are an integral part in such vastly diverse industrial sectors as automotive, aerospace, maritime, production, energy, health care, banking. Such systems are safety critical - human errors, technical failures, and malicious manipulation of information can cause catastrophic events leading to loss of life. Ove many years, critical incidents have been analyzed in detail but was has been searched for was the human error [16].

Human machine interaction plays a crucial role in these systems, in which typically expert users are controlling and interacting with complex systems.

$\mathrm{CHI}$ and other conferences recognize the importance of addressing the problems raised by non-classical User Interfaces. For instance, over the last decade, $\mathrm{CHI}$ has been featuring paper tracks on "Beyond the Desktop", addressing the issue of context of use and interactive systems that were supporting operators in performing their work. However, little to no work was targeting user interfaces for command and control interactive systems. So far, safety-critical interactions have not been in the focus of $\mathrm{CHI}$ yet. Novel methods and designs for interactions in large and complex settings do appear regularly at $\mathrm{CHI}$. On the other hand, conferences on formal methods or software engineering address the issues raised by the design of such system with a yet limited interest for the user interface part. Similarly, conferences on human factors or cognitive engineering mainly focus on the human side of these systems addressing high-level concepts such as automation, situation awareness in those contexts, but not with a focus on the human machine interaction per se, thus providing sub-optimal solutions with respect to current knowledge in the field of $\mathrm{HCI}$.

The deployment of more and more complex command and control systems has not yet received widespread attention by researchers and academia. Investigations in $\mathrm{HCI}$ are often centered on specific single-to-narrow-purpose interface in a specific context. The multi-faceted complexity of applicationoriented domains such as aerospace, maritime, health production, or energy (see also Figures 3-5) and the general and fundamental challenges they pose to human interaction did not get in the focus of $\mathrm{CHI}$ to a sufficient degree.

One dimension of the complexity of these safety-critical systems lies in the integration of all these devices to constitute a usable (efficient, effective, and satisfying to use) system.

Another dimension lies in the multiple stakeholders involved in the design, development, deployment, training, maintenance and certification of these systems.

The problems surrounding design of safety-critical interaction and safety-critical systems are receiving more and more public attention due to the increased deployment of these systems and the resulting failures. For instance, according to ${ }^{1}$, in 2019 the US Navy has reported removing touch technologies from the command and control systems of battleships following the collision between USS John S. McCain and USS Fitzgerald. The architecture of John S. McCain bridge (Figure 3 of that paper) highlights the multiplicity of operator workstations and technologies.

1 https://news.usni.org/2019/08/09/navy-reverting-ddgs-backto-physical-throttles-after-fleet-rejects-touchscreen-controls 


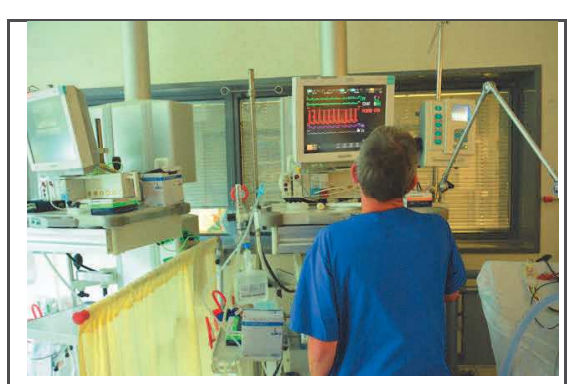

Figure 1. Nurse in an intensive care station monitoring alarms

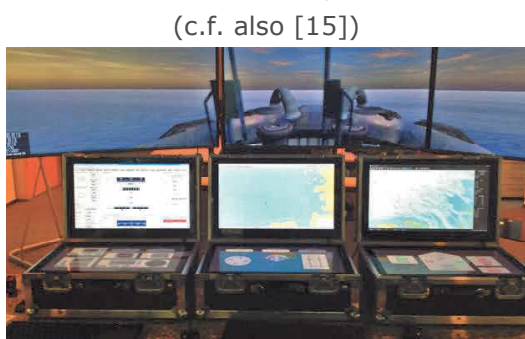

Figure 2 Ship bridge simulator environment studying safe navigation (c.f. also [13])

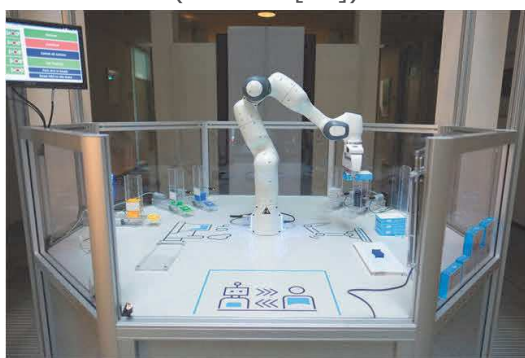

Figure 3 Human and machine interaction in a production line
In this workshop, we want to discuss practice, research, and current knowledge in the area of safety critical interactions. I is inspired by a very successful summer school on Safety Critical Interaction [[1]] and several events at $\mathrm{CHI}$ such as courses [[3]], workshops on the related topic of autonomous vehicles [[4]] or Special Interest Groups [[5]]. Similar events have been organized in other venues such as MobileHCI [[7]] and INTERACT [[2]]. These very well attended and successfu events allow to expect a well-attended workshop especially with the proximity of Asia that has been facing a major accident in the energy domain [[8]].

\section{Suitability for CHI}

Many $\mathrm{CHI}$ attendees are product designers and developers vitally concerned with improving the performance of their applications. Some of them will have the opportunity to extend their application domain to safety related ones.

This workshop is of immediate and practical benefit to such attendees because it allows them to hear and share the latest research problems and current solutions on this area.

To this end, this workshop will have an emphasis on case studies the organizers have been working on. This will provide useful and usable information of shared interest for both the academic researcher and the practitioners.

\section{Workshop goals}

The workshop has multiple goals in order to inform HCI research and practice for the design of large command and control systems.

- $\quad$ Provide a forum for researchers and designers of human interaction and user interfaces with an interest in safetycritical interfaces
- Identify commonalities and discrepencies amongst different application domains with respect to safety critical interactions and interfaces

- Discuss potential for transferring knowledge from usually unrelated domains such as transportation, energy and medicine

- Present research on potential solutions in terms of methods and processes for assessing safety of critical systems

- $\quad$ Envision new interaction paradigms for safety critical interactions taking into account a broader view of issues as, for instance [[9]] where touch interactions are enhanced with dependable mechanisms

- Explore engineering issues related to safety, reliability, and security properties as well as certification

- Consider UX factors relevant to the design of interactions within critical systems as identified in [[10]] with a focus on UX and automation.

\section{Participation}

The workshop is intended for HCI, Human Factors, and safety critical systems researchers and practitioners, designers and developers. Workshop candidates have to submit a position paper (four pages in the $\mathrm{CHI}$ extended abstract format

submitted via a submission system linked via the workshop website)

\section{Organizers}

We have comprehensive experience in the organization of conferences, workshops and summer schools in the area of safety-critical systems. This includes events at conferences such as CHI but also dedicated events such as the ATACCS (App. and Theory of Automation in Command and Control Sys) or the international summer school on $\mathrm{HCI}$ in safety critical environments [[1]]. 
Susanne Boll is Professor of Media Informatics and Multimedia Systems in the Department of Computing Science at the University of Oldenburg, in Germany. Her research interests lie in the field human computer interaction and pervasive computing with a strong application focus on safetycritical domains. Recently she has been working on interactive interface technology for ship bridges [12], multi-monitor environments [13], situation monitoring in large spaces [14], intensive care units [15]

Philippe Palanque is Professor in Computer Science at the University Toulouse 3. He is working on formal methods for engineering interactive systems and the application of such techniques to Higher Automation Levels in the field of Air Traffic Management, Interactive Cockpits of Large Civil Aircrafts [2] and Satellite Ground Segments [8]. He was chair of (Application and Theories of Automation in Command and Control Systems) ATACCS 2015 conference.

Alexander Mirnig is a Research Fellow at the Center for Human-Computer Interaction at the University of Salzburg, Austria. His research interests lie in interaction design in restricted environments, interaction with automation technologies, and Philosophy of Science. His current research focuses on human factors in automated public transportation [17], control transitions in semi-automated vehicles [20], and Machine Ethics [19].

Jessica Cauchard is an assistant professor in Industrial Engineering and Management at Ben Gurion University of the Negev, Israel. Her research interests lie in the fields of human computer interaction and ubiquitous computing. She has a strong interest in how people will interact with small autonomous devices in the future, such as drones [18] in collocated situations [24]. She investigates the role of collaboration in human and robotic environments [24]

Margaretha Lützhöft is a master mariner, trained at Kalmar Maritime Academy in Sweden. After leaving the sea, she studied for a Bachelor's degree in Cognitive science and a Master's in Computer Science. In 2004 she received a PhD in Human-Machine Interaction. Presently she is holding a position as Professor in the MarSafe group at the Western Norway University of Applied Sciences, and leader of the MarCATCH Research Centre. Her research interests include humancentered design and the effects of new technology [21] and the role that automation plays in the success and failure of navigation today [22] and the role of context [23].

Michael Feary is an aerospace technologist at NASA Ames research center where he leads the Aerospace Cognitive Engineering Lab. The ACE Lab investigates methods to improve the design and evaluation of complex, safety critical systems. The work centers on formal approaches to design and evaluation of human interaction with automated systems such as ADEPT tool [[26]]. He also organized events on automation at $\mathrm{CHI}$ such as [[5]].

\section{Website}

All the information about the workshop organization and program is published and updated on the workshop website https://sites.google.com/view/chi-ws-sci/welcome. The organizers have run several previous international events and have experience in setting up a professional Web page and advertisement of the workshop. It contains the call for participation including dates and author instructions and a link to a submission system for authors of position papers. It includes the background of each organizer and a detailed schedule of the workshop. Accepted position papers and presentations are available for download. 


\begin{tabular}{|c|c|}
\hline Time & Phases \\
\hline $\begin{array}{l}09: 00- \\
09: 10\end{array}$ & $\begin{array}{l}\text { Welcome and introduction } \\
\text { to workshop goals and } \\
\text { organization }\end{array}$ \\
\hline $\begin{array}{l}09: 10- \\
10: 30\end{array}$ & $\begin{array}{l}\text { Position Paper } \\
\text { Presentations I } \\
\text { (presentations } 10 \text { min } \\
\text { each incl. Q\&A) }\end{array}$ \\
\hline $\begin{array}{l}10: 30- \\
10: 45\end{array}$ & Coffee break \\
\hline $\begin{array}{l}10: 45- \\
12: 15\end{array}$ & $\begin{array}{l}\text { Position Paper } \\
\text { Presentations II } \\
\text { (presentations } 10 \mathrm{~min} \\
\text { each incl. Q\&A) }\end{array}$ \\
\hline $\begin{array}{l}12: 15- \\
13: 30\end{array}$ & Lunch \\
\hline $\begin{array}{l}13: 30- \\
15: 10\end{array}$ & $\begin{array}{l}\text { Group discussions on } 5 \\
\text { tables/themes ( } 20 \text { minutes } \\
\text { slots for each participant } \\
\text { on every table) }\end{array}$ \\
\hline $\begin{array}{l}15: 10- \\
15: 30\end{array}$ & Coffee break \\
\hline $\begin{array}{l}15: 30- \\
16: 45\end{array}$ & $\begin{array}{l}\text { Presentation of results } \\
\text { from each table (15 min } \\
\text { each) }\end{array}$ \\
\hline $\begin{array}{l}16: 45- \\
17: 00\end{array}$ & $\begin{array}{l}\text { Exploration of future work } \\
\text { (e.g., joint publication) } \\
\text { and wrap-up }\end{array}$ \\
\hline later & $\begin{array}{l}\text { Joint workshop dinner } \\
\text { (optional) }\end{array}$ \\
\hline
\end{tabular}

Table 1: Workshop schedule.

\section{Pre-Workshop Plans}

The call for participation (CFP) will be distributed via HCI-,

Human Factors and Ergonomics Society and safety mailing lists (e.g., chi-announcements, systemsafety@lists.techfak.unibielefeld.de), social networks (e.g., Facebook groups and Twitter), as well as personal distribution lists based on workshops and conferences we have held. Accepted workshop position papers will be made available to all participants via the workshop website before the workshop to foster interactions during the workshop.

\section{Workshop Structure}

This will be a one-day workshop consisting of approximately 20 participants plus organizers. Table 1 provides an overview of the proposed workshop schedule.

Participants will be welcomed and introduced into workshop goals. The first half of the workshop-day will be dedicated to oral presentation of the position papers, reflections, and discussions on the presentations of each participant. Participants will be provided with a 10-minute slot each including Q\&A. Presentations should be short, straight to the point and convey a clear message in line with the workshop objectives.

The second half of the workshop will be dedicated to participant discussions and collaborations. Participants will discuss challenges of safety critical interaction and interfaces from various perspectives. There will be five tables each hosting a specific topic (e.g., certification, global design, human error, human as hero, conflicts and tradeoffs between properties (e.g. UX, usability, safety, dependability etc.). Topics will be finalized based on position paper submissions and the discussion in the morning sessions. Each table will

2 https://academic.oup.com/iwc have a host (one of the organizers). After 20 minutes, every participant will move to another table to ensure that by the end of the workshop each participant has discussed each topic. Finally, a group session will be held, in which topic hosts will present results. In a wrap up phase potentials for a joint publication and/or a special issue on the topic will be discussed.

\section{Post-Workshop Plans}

Workshop results will be communicated both to communities and a general audience including a Poster at CHI. We plan to produce a report for publication in the ACM Interactions magazine and prepare a special issue in a selected journal

(e.g. Interacting with Computers ${ }^{2}$ ) following the conference. This will depend of the quality of the contributions and of the output of the workshop. Workshop results will be made

available through the workshop website and an email list to network with others will be created.

\section{Call for Participation}

Designing Safety Critical Interactions: Hunting Down Human Error is a one-day workshop at CHI 2020 in Hawaii, USA.

This workshop is aimed at researchers and designers in the field of human-computer interaction. In this workshop, we want to discuss practice, research and current knowledge in safety critical interactions and how to design for avoiding human error in future complex interactive systems. We will discuss how the design process and methods need to change or be adapted to avoid human error in safety-critical environments already at design time. What can be learnt from other domains for the design and evaluation of autonomous vehicles. 
To participate, a four-page paper in the $\mathrm{CHI}$ extended abstract format has to be submitted via the workshop website. Position papers should cover one of the following or related topics:

- interactive Systems for understanding and resolving critical situations

- Design for safety, reliability and security in interactive systems

- Designing for resilience in interactive systems

- Metrics for evaluating interactions in complex safetycritical systems

- Collaboration in safety critical environments

- The role of simulation and models for safety critical interaction design

- Participatory design and ethnography for safety critical interaction design

- Interaction across multiple devices from multiple brands in safety-critical environments

- commonalities and discrepencies amongst different application domains

The workshop is restricted to approximately 20 participants. Applications will be selected by workshop chairs, who will evaluate position papers based on their fit with the workshop theme, their originality, and their quality. The author of an accepted submission must attend the workshop, provide a short presentation, and register for both the workshop and for at least one day of the main conference.

\section{Deadlines}

- Position paper: February 11, 2020

- Notification: February 28, 2020

- Workshop at CHI2020: April 25th/26th, 2020

More Information:

https://sites.google.com/view/chi-ws-sci/welcome

\section{References}

1] Boll S., HCI4Safety International Summer School on Human Computer Interaction in Safety Critical Environments, July 1st to 5th, 2019, Oldenburg, Germany, https://hci4safety.offis.de/

[2] Palanque P., Martinie C., Bouzékri E. (2019) Introduction to Automation and to Its Potential for Interactive Systems Design. Human-Computer Interaction. INTERACT 2019. Lecture Notes in Computer Science, vol 11749. Springer,

[3] Palanque P., Célia Martinie, and Camille Fayollas. 2018. Automation: Danger or Opportunity? Designing and Assessing Automation for Interactive Systems. In Extended Abstracts of the $2018 \mathrm{CHI}$ Conference on Human Factors in Computing Systems (CHI EA '18). ACM, New York, NY, USA, Paper C19, 4 pages.

[4] Meschtscherjakov A., Manfred Tscheligi, Bastian Pfleging, Shadan Sadeghian Borojeni, Wendy Ju, Philippe Palanque, Andreas Riener, Bilge Mutlu, and Andrew L. Kun. 2018. Interacting with Autonomous Vehicles: Learning from other Domains. 2018 CHI(Extended Abstracts) Conf. on Human Factors in Computing Systems. ACM, 8 p.

[5] Feary M., Célia Martinie, Philippe Palanque, and Manfred Tscheligi. 2016. Multiple Views on Safety-Critical Automation: Aircrafts, Autonomous Vehicles, Air Traffic Management and Satellite Ground Segments Perspectives 2016 CHI Conference (CHI EA '16). ACM, 1069-1072.

[6] Bernhaupt R., Guy Boy, Michael Feary, and Philippe Palanque. 2011. Engineering automation in interactive critical systems. In CHI '11 Extended Abstracts on Human Factors in Computing Systems (CHI EA '11). ACM, New York, NY, USA, 69-72

[7] Meschtscherjakov A., Manfred Tscheligi, Peter Fröhlich, Rod McCall, Andreas Riener and Philippe Palanque. 2017. Mobile Interaction with and in Autonomous Vehicles. 19th Int. Conf. on Human-Computer Interaction with Mobile Devices and Services, MobileHCI '17, ACM 78:1-78:6.

[8] Fujita, "Learning from the Fukushima nuclear power plant accident - A resilience point of view," 2012 Southeast Asian Network of Ergonomics Societies Conference (SEANES), Langkawi, Kedah, 2012, pp. 1-5, IEEE explore.

[9] Palanque P., Andy Cockburn, Léopold Désert-Legendre, Carl Gutwin, Yannick Deleris. Brace Touch: A Dependable, Turbulence-Tolerant, Multi-touch Interaction Technique fo 
Interactive Cockpits. SAFECOMP 2019, LNCS 11608, p 5368

[10] Roto V., Palanque P., Karvonen H. (2019) Engaging Automation at Work - A Literature Review. Human Work Interaction Design. Designing Engaging Automation. HWID 2018. IFIP Advances in Information and Communication Technology, vol 544. Springer

[11] ATACCS conference series. Application and Theory of Automation in Command and Control Systems https://www.irit.fr/recherches/ICS/events/conferences/at accs/ataccs2015/

[12] Stratmann T. C., Dierk Brauer, and Susanne Boll. 2019. Supporting the Perception of Spatially Distributed 2019 (MuC'19). ACM, New York, NY, USA, 475-479.

[13] Stratmann T. C., Felix Kempa, and Susanne Boll. 2019. LAME: light-controlled attention guidance for multimonitor environments. 8th ACM Int. Symposium on Pervasive Displays (PerDis '19). ACM, Article 7, 5 pages.

[14] Gruenefeld U., Abdallah El Ali, Wilko Heuten, and Susanne Boll. 2017. Visualizing out-of-view objects in headmounted augmented reality. In Proceedings of the 19th with Morile Devices and Sevices (MobileHCI '17). ACM, Article 81,7 pages.

[15] Cobus V., Heuten W., and Boll S. 2017. Multimodal headmounted display for multimodal alarms in intensive care units. In PerDis '17. ACM, Article 26, 2 pages.

[16] Stratmann T. C. and Boll S. (2016) Demon Hunt -The role of Endsley's demons of situation awareness in maritime accidents. Human-Centered and Error-Resilient System Development. LNCS (9856). Springer pp. 203-212.

[17] Mirnig A. G., Philipp Wintersberger, Alexander Meschtscherjakov, Andreas Riener, and Susanne Boll. 2018. Workshop on Communication between Automated Vehicles and Vulnerable Road Users. Adjunct Proceeding of AutomotiveUI '18. ACM, New York, NY, USA, 65-71.

[18] Cauchard J. R., Alex Tamkin, Cheng Yao Wang, Luke Vink, Michelle Park, Tommy Fang, and James A. Landay. 2019. Drone.io: A Gestural and Visual Interface for HumanDrone Interaction, 14th ACM/IEEE International Conference on Human-Robot Interaction (HRI), pp. 153162.
[19] Mirnig A. G. and Alexander Meschtscherjakov. 2019. On What Matters for Ethical Decision Making in Automated Vehicles. 2019 CHI 19). 19). ACM, Paper 509, 10 pages.

[20] Trösterer S., Meschtscherjakov A., Mirnig A.G., Artur Lupp, Magdalena Gärtner, Fintan McGee, Rod McCall, Manfred Tscheligi, and Thomas Engel. What We Can Learn from Pilots for Handovers and (De)Skilling in SemiAutonomous Driving: An Interview Study 9th Intl. Conf Autonous Applications (AutomotiveUI '17). ACM, 173-182.

[21] Lützhöft M., The technology is great when it works": Maritime Technology and Human Integration on the Ship's Bridge. Linköping: Linköping University Electronic Press, 2004. p. 108

[22] M. H. Lützhöft and S. W. A. Dekker. On Your Watch: Automation on the Bridge, Cambridge University Press: 14 February 2002

[23] Relling T., Lützhöft M. Ostnes R, Hildre H.P. (2018) A Human Perspective on Maritime Autonomy. In: Schmorrow D., Fidopiastis C. (eds) Augmented Cognition: Users and Contexts. AC 2018. Lecture Notes in Computer Science, vol 10916. Springer, Cham

[24] Baillie L., Cynthia Breazeal, Pete Denman, Mary Ellen Foster, Kerstin Fischer, and Jessica R. Cauchard. 2019. The Challenges of Working on Social Robots that Collaborate with People. In Extended Abstracts of the 2019 CHI Conf on Human Factors in Computing Systems. ACM, New York, NY, USA, Paper W12, 7 pages.

[25] Wojciechowska A., J. Frey, S. Sass, R. Shafir and J. R. Cauchard, "Collocated Human-Drone Interaction: Methodology and Approach Strategy," 2019 14th ACM/IEEE International Conference on Human-Robot Interaction (HRI), Daegu, Korea (South), 2019, pp. 172 181

[26] Billman D., Fayollas C., Feary M., Martinie C., Palanque P. (2016) Complementary Tools and Techniques for Supporting Fitness-for-Purpose of Interactive Critical Sysporting Fitness-for-Purpose of Interactive Critical Systems. Human-Centered and Error-Resilient Systems Springer,
Sevel. HESD 2016, HCSE 2016. LNCS, vol 9856. 